\title{
ANALISIS USAHA AGROINDUSTRI TAHU \\ (Studi Kasus pada Perajin Agroindustri Tahu di Desa Parigi Kecamatan Parigi Kabupaten Pangandaran)
}

\author{
IRFAN SURYANA*, AGUS YUNIAWAN ISYANTO, SUDRAJAT \\ Fakultas Pertanian Universitas Galuh \\ *E-mail : irfansuryana@yahoo.com
}

\begin{abstract}
ABSTRAK
Penelitian ini bertujuan untuk mengetahui: 1) Besarnya biaya yang dikeluarkan pada agroindustri tahu dalam satu kali proses Produksi, 2) Besarnya penerimaan dan pendapatan dari agroindustri tahu dalam satu kali proses produksi, 3) Besarnya R/C pada agroindustri tahu dalam satu kali proses produksi. Penelitian ini dilaksanakan di Desa Parigi Kecamatan Parigi Kabupaten Pangandaran dengan menggunakan Metode Studi Kasus. Perajin tahu yang berada di Desa Parigi yaitu ada tiga orang semuanya dijadikan sebagai sampel (sampling jenuh). Data yang diperoleh dianalisis secara deskriptif kuantitatif. Analisis dilakukan dalam satu kali proses produksi selama satu hari. Hasil penelitian menunjukkan bahwa: a) Besarnya biaya rata-rata yang dikeluarkan oleh tiga orang perajin tahu yang berada di Desa Parigi Kecamatan Parigi Kabupaten Pangandaran adalah Rp 884.736,- dalam satu kali proses produksi. b) Besarnya rata-rata penerimaan yang diperoleh tiga orang perajin agroindustri tahu di Desa Parigi Kecamatan Parigi Kabupaten Pangandaran Rp 1.413.400,- dan besarnya pendapatan yang diperoleh perajin adalah Rp 528,663,- dalam satu kali produksi. c) Rata-rata $\mathrm{t} \mathrm{R} / \mathrm{C}$ dari tiga perajin usaha agroindustri tahu yaitu 1,58. Artinya usaha yang dilakukan menguntungkan dan layak diteruskan karena nilai R/C nya lebih dari 1.
\end{abstract}

Kata Kunci: Agroindustri, Perajin, Tahu.

\section{ABSTRACT}

This study aims to find out: 1) The amount of costs incurred in tofu agroindustry in one production process, 2) The amount of revenue and income from tofu agroindustry in one production process, 3) The amount of $R / C$ in tofu agroindustry in one production process. This research was conducted in Parigi Village, Parigi District, Pangandaran Regency by using Case Study Method. The tofu craftsmen in Parigi Village, there are three people all made as samples (saturated sampling). The data obtained were analyzed descriptively quantitatively. Analysis is carried out in one production process for one day. The results showed that: a) The average cost incurred by three tofu artisans in Parigi Village, Parigi District, Pangandaran Regency was Rp. 884.736,- in one production process. b) The amount of average income obtained by three tofu agroindustry craftsmen in Parigi Village, Parigi District, Pangandaran Regency Rp. 1,413,400, - and the amount of income earned by crafters is Rp. 528,663 ,- in one production. c) The average $t R / C$ of the three tofu producers is 1.58 . This means that the business carried out is profitable and is worth continuing because the $R$ / $C$ value is more than 1.

Keywords: Agroindustry, Crafters, Tofu.

\section{PENDAHULUAN}

Sektor pertanian salah satu sektor utama dalam perekonomian bangsa Indonesia. Hampir semua sektor yang ada di Indonesia tidak lepas dari sektor pertanian. Potensi alam yang dimiliki Indonesia menjadikan negara Indonesia menjadi negara yang subur dengan beraneka ragam flora dan fauna yang dapat tumbuh dan berkembang di. Indonesia mayoritas sektor petanian dijadikan sebagai sumber penghidupan oleh masyarakat indonesia (Sudaryanto \& Syafa'at, 2002). 
Hanani \& Ibrahim dalam Hermanto, dkk., (2015) menyatakan bahwa pengembangan agroindustri sebagai langkah industrialisasi perdesaan merupakan pilihan strategi yang tepat karena agroindustri dapat menciptakan lapangan kerja dan memberikan nilai tambah.
Salah satu komoditi pertanian yang berpotensi untuk dikembangkan di Kabupaten Pangandaran adalah tanaman kedelai. Saat ini kedelai diusahakan oleh para petani yang tersebar di seluruh kecamatan, seperti pada Tabel 1 dengan perincian luas tanam, luas panen dan luas puso di setiap kecamatan.

Tabel 1. Luas Tanam, Luas Panen dan Luas Puso Tanaman Kedelai di Kabupaten Pangandaran Tahun 2018

\begin{tabular}{clccc}
\hline NO & Kecamatan & Luas Tanam (ha) & Luas Panen (ha) & Luas Puso (ha) \\
\hline 1 & Cimerak & 40,00 & 225,00 & - \\
2 & Cijulang & 75,00 & 85,00 & - \\
3 & Cigugur & 3,00 & 80,00 & - \\
4 & Langkaplancar & 315,00 & 630,00 & - \\
5 & Parigi & 80,00 & 120,00 & 10,00 \\
6 & Sidamulih & 50,00 & 50,00 & - \\
7 & Pangandaran & 65,00 & 105,00 & - \\
8 & Kalipucang & 162,00 & 420,00 & - \\
9 & Padaherang & 950,00 & 920,00 & 270,00 \\
10 & Mangunjaya & 63,00 & 110,00 & - \\
& Jumlah & $\mathbf{1 . 8 0 3 , 0 0}$ & $\mathbf{2 . 7 4 5 , 0 0}$ & $\mathbf{2 8 0 , 0 0}$ \\
\hline
\end{tabular}

Sumber: Dinas Pertanian Kabupaten Pangandaran, 2018

Tabel 1 menunjukkan bahwa luas tanam kedelai di Kabupaten Pangandaran seluas $1.803,00$ ha, luas panen $2.745,00$ ha, luas puso 280,00 ha. Sedangkan untuk data produksi dan produtivitas kedelai di Kabupaten Pangandaran seperti pada Tabel berikut.

Tabel 2. Jumlah Produksi dan Produktivitas Tanaman Kedelai di Kabupaten Pangandaran Tahun 2018

\begin{tabular}{clccc}
\hline NO & \multicolumn{1}{c}{ Kecamatan } & Luas Panen (ha) & Produksi (ton) & Protas (ton/ha) \\
\hline 1 & Cimerak & 225,00 & 325,74 & 1,5 \\
2 & Cijulang & 85,00 & 128,29 & 1,5 \\
3 & Cigugur & 80,00 & 117,20 & 1,5 \\
4 & Langkaplancar & 630,00 & 931,12 & 1,5 \\
5 & Parigi & 120,00 & 177,07 & 1,4 \\
6 & Sidamulih & 50,00 & 73,90 & 1,4 \\
7 & Pangandaran & 105,00 & 159,29 & 1,5 \\
8 & Kalipucang & 420,00 & 632,53 & 1,5 \\
9 & Padaherang & 920,00 & $1.453,50$ & 1,5 \\
10 & Mangunjaya & 110,00 & 178,11 & 1,6 \\
& Jumlah & $\mathbf{2 . 7 4 5 , 0 0}$ & $\mathbf{4 . 1 7 6 , 7 4}$ & $\mathbf{1 4 , 9}$ \\
\end{tabular}

Sumber: Dinas Pertanian Kabupaten Pangandaran, 2018 
Tabel 2 menunjukkan bahwa di Kabupaten Pangandaran luas panen kedelai seluas $2.745,00$ ha dengan jumlah produksi 4.176,74 ton dan produktivitasnya 14,9 ton/ha.

Adisarwanto (2008) menyatakan kedelai sebagai komoditi tanaman pangan fungsinya menjadi amat penting dan strategis dalam ekonomi nasional, karena memiliki peran untuk memenuhi kebutuhan industri, Pangan dan pakan dalam negeri yang terus menerus semakin meningkat. Permintaan yang meningkat tersebut pada dasarnya didorong dengan meningkatnya industri tahu, tempe, kecap dan pakan. kekurangan bahan baku kedelai akan terus meningkat di masa depan

Agroindustri yang berbahan baku kedelai berpotensi untuk dikembangkan di Kabupaten Pangandaran. Agroindustri tersebut di Kecamatan Parigi merupakan yang terbanyak di Kabupaten Pangandaran dan terletak di pusat Kabupaten Pangandaran, sebagaimana dapat dilihat pada Tabel 3.

Tabel 3. Data Industri Kecil dan Menengah Industri Olahan Kedelai di Kecamatan Parigi Kabupaten Pangandaran Tahun 2018

\begin{tabular}{|c|c|c|c|c|c|c|c|c|}
\hline \multirow[t]{2}{*}{ No } & \multirow{2}{*}{$\begin{array}{c}\text { Nama } \\
\text { Perusahaan }\end{array}$} & \multirow{2}{*}{$\begin{array}{l}\text { Nama } \\
\text { Pemilik }\end{array}$} & \multirow[t]{2}{*}{ Desa } & \multirow{2}{*}{$\begin{array}{l}\text { Nama } \\
\text { Produk }\end{array}$} & \multirow{2}{*}{$\begin{array}{l}\text { Tenaga } \\
\text { Kerja }\end{array}$} & \multirow{2}{*}{$\begin{array}{l}\text { Nilai Investasi } \\
\text { (Rp) }\end{array}$} & \multicolumn{2}{|c|}{$\begin{array}{c}\text { Kapasitas } \\
\text { Produk/Bulan }\end{array}$} \\
\hline & & & & & & & Jumlah & Satuan \\
\hline 1 & 2 & 3 & 4 & 5 & 6 & 7 & 8 & 9 \\
\hline 1 & Sinar Galih & Usin & $\begin{array}{l}\text { Parakan } \\
\text { Manggu }\end{array}$ & Tempe & 3 & & 100 & $\mathrm{~kg}$ \\
\hline 2 & Tahu, Tempe & H. Cepi & Bojong & Tahu, Tempe & 3 & 20.000 .000 & & \\
\hline 3 & Kuswanda & Kuswanda & Karangbenda & Tahu, Tempe & 3 & & & \\
\hline 4 & & Sarno & Cintakarya & Tahu, Tempe & 2 & 6.000 .000 & & \\
\hline 5 & & Kusnadi & Parigi & Tempe & 2 & 3.000 .000 & & \\
\hline 6 & & Aan Hasanah & Parigi & Tempe & 2 & 3.000 .000 & & \\
\hline 7 & & Mariah & Cibenda & Tempe & 2 & 2.600 .000 & & \\
\hline 8 & Nana & Nana & Karangbenda & Tahu & 3 & & & \\
\hline 9 & & Undang $\mathrm{S}$ & Parigi & Tahu & 2 & 4.000 .000 & & \\
\hline 10 & & Ating & Parigi & Tahu & 3 & 8.000 .000 & & \\
\hline 11 & & Uus & Parigi & Tahu & 2 & 5.000 .000 & & \\
\hline 12 & & Suradi & Parigi & Keripik & 2 & 3.000 .000 & & \\
\hline 13 & $\begin{array}{l}\text { PD Usaha } \\
\text { Bersama }\end{array}$ & $\begin{array}{l}\text { Ayat } \\
\text { Nurhidayat }\end{array}$ & Cintakarya & $\begin{array}{l}\text { Kembang } \\
\text { tahu }\end{array}$ & 4 & 1.300 .000 & & \\
\hline 14 & & Haerudin & Cibenda & Kecap & 5 & & & \\
\hline 15 & & H. Ahmad & Cibenda & Kecap & 3 & & & \\
\hline 16 & & E Rahmat & Parigi & Kecap & 3 & 30.000 .000 & & \\
\hline & & Jumlah & & & 57 & 85.900 .000 & 100 & \\
\hline
\end{tabular}

Sumber: Dinas Tenaga Kerja Industri dan Transmigrasi Kabupaten Pangandaran, 2018

Tabel 3 menunjukkan bahwa Desa Parigi merupakan desa yang paling banyak memiliki agroindustri tahu di Kabupaten Pangandaran yaitu sebanyak 3 unit.
Untuk mengetahui berapa besarnya keuntungan yang diperoleh ketiga agroindustri tahu tersebut, maka penulis melakukan penelitian mengenai Analisis 
Usaha Agroindustri Tahu di Desa Parigi

Kecamatan Parigi Kabupaten Pangandaran.

\section{METODE PENELITIAN}

\section{Jenis Penelitian}

Jenis penelitian yang digunakan dalam penelitian ini adalah studi kasus. Menurut Daniel (2002), studi kasus mirip dengan metode survei, bedanya dalam studi kasus, populasi yang diteliti lebih terarah atau terfokus pada suatu sifat tertentu yang tidak berlaku umum. Biasanya dibatasi oleh kasus, tempat, serta waktu tertentu.

\section{Operasionalisasi Variabel}

Variabel-variabel yang diamati dalam penelitian ini sebagai berikut:

(1) Satu kali proses produksi adalah dimulai dari penyediaan bahan baku, pengolahan, sampai tahu siap dipasarkan yang membutuhkan waktu selama satu hari.

(2) Biaya produksi terdiri atas biaya tetap dan biaya variabel yang dinyatakan dalam satuan rupiah per satu kali proses produksi.

(a) Biaya tetap merupakan biaya yang besar kecilnya tidak dipengaruhi oleh biaya produksi dan sifatnya tidak akan habis dalam satu kali produksi. Biaya tetap terdiri atas:
1. Pajak bumi dan bangunan yang digunakan dalam mengusahakan agroindustri tahu dihitung dalam satuan meter persegi $\left(\mathrm{m}^{2}\right)$, dinyatakan dengan satuan rupiah per satu kali proses produksi.

2. Penyusutan alat dan bangunan dihitung per satu kali proses produksi.

3. Bunga modal tetap dihitung dalam satuan persen berdasarkan bunga bank yang berlaku pada saat penelitian dan dinyatakan dalam satuan rupiah dalam proses produksi.

(b)Biaya variabel adalah biaya yang nilainya tergantung pada besar kecilnya produksi dan bersifat habis dalam satu kali proses produksi. Biaya Variabel terdiri atas:

4. Kedelai yang digunakan dihitung dalam satuan kilogram $(\mathrm{Kg})$ dan dinyatakan dalam satuan rupiah dalam satu kali proses produksi.

5. Kayu bakar diukur dalam satuan meter kubik $\left(\mathrm{m}^{3}\right)$ dan dinyatakan dalam satuan rupiah per proses produksi.

6. Bahan pelengkap, yaitu:

a. Plastik pembungkus dihitung dalam satuan pak dan dinyatakan dalam satuan 
rupiah selama satu kali proses produksi.

b. Cuka dihitung dalam satuan liter dan dinilai dalam satuan rupiah selama satu kali proses produksi.

c. Bahan bakar, dihitung dalam satuan liter dan dinilai dalam satuan rupiah selama satu kali proses produksi.

d. Tranportasi, dihitung dalam satuan rupiah selama satu kali proses produksi.

7. Upah tenaga kerja, yaitu tenaga kerja yang digunakan untuk agroindustri tahu, baik tenaga kerja keluarga maupun tenaga kerja luar keluarga, dinyatakan dalam satuan rupiah per proses produksi.

8. Bunga modal variabel dihitung dalam satuan persen berdasarkan bunga bank yang berlaku pada saat penelitian dan dinyatakan dalam satuan rupiah selama satu kali proses produksi.

(3) Penerimaan yaitu jumlah hasil produksi dikali harga jual produk, dinyatakan dalam satuan rupiah per proses produksi.

1. Hasil produksi dihitung dalam satuan buah.
2. Harga jual dihitung dalam satuan rupiah per buah (Rp/buah)

(4) Pendapatan perajin tahu yaitu penerimaan dari perajin tahu dikurangi biaya produksi, dinyatakan dalam satuan rupiah (Rp) per proses produksi.

Asumsi yang digunakan dalam penelitian ini adalah:

a. Produk yang diproduksi habis terjual

b. Harga input dan output adalah harga yang berlaku pada saat penelitian

\section{Teknik Pengumpulan Data}

Jenis data yang dikumpulkan dalam penelitian ini meliputi data primer, yaitu data yang diperoleh dari responden dengan cara wawancara langsung dengan menggunakan data pertanyaan yang telah dipersiapkan, dan data sekunder, yaitu data yang diperoleh dari lembaga-lembaga terkait dengan penelitian ini dan dari studi literatur.

\section{Teknik Penarikan Sampel}

Penarikan sampel dalam penelitian ini menggunakan teknik penarikan sampel purposive sampling jenuh atau sensus. Sampling jenuh atau sensus adalah teknik 
pemilihan sampel bila semua anggota populasi akan digunakan sebagai sampel. Istilah lain sampling jenuh adalah sensus (Sugiyono, 2007). Jumlah perajin tahu di Desa Parigi sebanyak 3 orang, maka seluruh perajin tersebut dijadikan sebagai sampel.

\section{Rancangan Analisis Data}

Besarnya biaya, penerimaan dan pendapatan pada agroindustri tahu dianalisis sebagai berikut:

(1) Analisis Biaya

Biaya dihitung dengan menggunakan rumus sebagai berikut (Soekartawi, 2002):

$\mathrm{TC}=\mathrm{TFC}+\mathrm{TVC}$

Dimana:

$\mathrm{TC}=$ Total Cost (Biaya Total)

TFC = Total Fixed Cost (Biaya

Tetap Total)

TVC $=$ Total Variable Cost (Biaya Variabel Total)

(2) Analisis Penerimaan

Penerimaan dihitung dengan menggunakan rumus sebagai berikut (Suratiyah, 2006):

$\mathrm{P}=\mathrm{Py}$. Y

Dimana:

$\mathrm{P}=$ Penerimaan

Py $=$ Harga Produksi (Rp/buah)

$\mathrm{Y}=$ Jumlah Produksi (Buah)
(3) Analisis Pendapatan

Pendapatan dihitung dengan menggunakan rumus sebagai berikut (Suratiyah, 2006):

$\mathrm{Pd}=\mathrm{P}-\mathrm{TC}$

Dimana:

$\mathrm{Pd}=$ Pendapatan

$\mathrm{P}=$ Penerimaan

$\mathrm{TC}=$ Total Cost (Biaya Total)

(4) Analisis R/C

Rumus yang digunakan untuk mengetahui imbangan antara penerimaan dengan biaya adalah sebagai berikut (Soekartawi, 2002):

$\mathrm{R} / \mathrm{C}=\mathrm{TR} / \mathrm{TC}$

Dimana:

$\mathrm{R} / \mathrm{C}=$ Revenue Cost Ratio

$\mathrm{TR}=$ Total Revenue (Penerimaan Total)

$\mathrm{TC}=$ Total Cost (Biaya Total)

\section{Tempat dan Waktu Penelitian}

Penelitian ini dilaksanakan di Desa Parigi Kecamatan Parigi Kabupaten Pangandaran. Adapun waktu penelitian dibagi dalam 3 tahap yaitu :

1) Tahap persiapan, yaitu tahap penjajakan (survey ke lapangan), dan penulisan Usulan Penelitian dilaksanakan pada bulan Januari sampai Maret 2019. 
2) Tahap pengumpulan data dari lapangan, yaitu pengumpulan data primer dan sekunder dilaksanakan pada bulan April 2019.

3) Tahap pengolahan dan analisis data, serta penulisan Skripsi dilaksanakan pada bulan Mei 2019 sampai dengan selesai.

\section{HASIL DAN PEMBAHASAN}

\section{Karakteristik Responden}

Responden penelitian sebanyak 3 orang, ketiga orang tersebut adalah perajin agroindustri tahu di Desa Parigi Kabupaten Pangandaran. Berdasarkan hasil penelitian terhadap ketiga responden dapat diketahui identitas masing-masing. Untuk lebih jelasnya dapat dilihat pada uraian berikut.

\section{Umur Responden}

Berdasarkan hasil penelitian, maka dapat diketahui umur ketiga responden yaitu 37 - 49 tahun. Menurut Hartono (2009) menyatakan bahwa penduduk usia non produktif usia dari $0-14$ dan $\searrow 64$ tahun. Sedangkan penduduk yang produktif usia dari 15-64 Tahun. Ketiga respoden termasuk usia produktif.

\section{Tingkat Pendidikan responden}

Pendidikan adalah hal yang penting untuk meningkatkan sumber daya manusia
(SDM) baik pendidikan formal maupun non formal. Dari hasil penelitian tingkat pendidikan dari ketiga responden lulusan SMP (Sekolah Menengah Pertama) 2 orang dan 1 orang lulusan SMA (Sekolah Menengah Atas).

\section{Pengalaman Usaha Responden}

Pengalaman merupakan guru yang paling baik, begitupula dalam pengalaman agroindustri, pengalaman yang cukup lama diharapkan akan menunjang terhadap keberhasilan dan pengembangan usaha. Pengalaman responden sebagai perajin agroindustri tahu 10 - 15 Tahun.

\section{Jumlah Tanggungan Keluarga}

Banyaknya jumlah tanggungan keluarga perajin tahu akan berpengaruh terhadap tingkat kesejahteraan keluarga. Perajin tahu mempunyai tanggungan keluarga sebanyak $2-3$ tanggungan keluarga. Semakin besar tanggungan keluarga akan memacu perajin lebih giat lagi dalam melakukan usahanya.

Pelaksanaan Kegiatan Usaha Agroindustri Tahu

\section{Penyediaan Sarana Produksi}

Penyediaan sarana produksi dalam usaha agroindustri tahu yang ada di Desa Parigi dilakukan langsung oleh perajin 
termasuk dalam mengadakan alat-alat yang dilakukan pada usaha agroindustri tahu, untuk pengadaan bahan baku kedelai, perajin membeli bahan baku dari petani kedelai di Kota Banjar.

Langkah-langkah pembuatan tahu yang biasa dilakukan oleh perajin agroindustri tahu yang ada di Desa Parigi kecamatan Parigi Kabupaten Pangandaran adalah sebagai berikut :

1. Pencucian dan perendaman

Kedelai yang digunakan sebanyak 15 kilogram setiap adonannya (jirangan), pada tahap awal, kacang kedelai direndam dengan air selama 8-12 jam selama satu malam. Hal ini dilakukan untuk memisahkan dari kedelai yang rusak atau busuk dan pecah.

\section{Penggilingan}

Setelah di rendam kedelai kemudian dimasukan ke mesin penggiling untuk dijadikan bubur halus, selama penggilingan berlangsung harus ditambah air sedikit demi sedikit kemudian ditampung kedalam tong.

3. Pemasakan atau penggumpalan

Bubur kedelai dimasak sampai mendidih, kemudian ditambahkan air sedikit demi sedikit, bubur kedelai kemudian disaring untuk mengambil sarinya dan ampasnya dibuang atau bisa juga dikumpulkan untuk dijual. Sari kedelai kemudian dimasukan ke dalam tong besar lalu digumpalkan dengan menggunakan asam cuka, kemudian aduk-aduk sampai menggumpal, kemudian diendapkan hingga gumpalan turun ke dasar wadah dan airnya dibuang, lalu dimasukkan kedalam cetakan yang telah dialasi kain kasa kemudian dipress dan siap dicetak.

4. Bubur tahu yang sudah dipress kemudian siap untuk dicetak sesuai dengan ukuran yang dikehendaki. Untuk pencetakan, para perajin tahu di Desa Parigi mencetak ukuran tahu yang dijual ke pasar dengan harga Rp. 300 per buah.

\section{Analisis Usaha Agroindustri Tahu}

Analisis usaha aroindustri tahu terdiri dari analisis biaya, penerimaan, pendapatan, dan R/C yang dihitung selama satu kali proses produksi dalam satu hari. Adapun bunga modal untuk tahun ini yaitu $9,5 \%$ pertahun.

\section{Analisis Biaya Usaha Agroindustri Tahu \\ Biaya yang dihitung dari responden adalah biaya yang digunakan dalam usaha agroindustri tahu dalam satu kali proses}


produksi yang dibagi menjadi dua jenis biaya yaitu :

1. Biaya tetap (fixed cost) adalah biaya yang besar kecilnya tidak dipengaruhi oleh besar kecilnya volume produksi dan sifatnya tidak habis dalam satu kali proses produksi, yang terdiri dari pajak bumi dan bangunan, penyusutan alat, dan bunga modal. Biaya tetap pada agroindustri tahu di Desa Parigi dapat diamati pada Tabel 9.

Tabel 9. Rata-rata Biaya Tetap Pada Usaha Agroindustri Tahu dalam Satu Kali Proses Produksi di Desa Parigi

\begin{tabular}{crrrr}
\hline No. Responden & $\begin{array}{c}\text { Pajak Bumi } \\
\text { dan Bangunan } \\
(\mathbf{R p})\end{array}$ & $\begin{array}{c}\text { Penyusutan Alat } \\
(\mathbf{R p})\end{array}$ & $\begin{array}{c}\text { Bunga } \\
\text { Modal } \\
(\text { Rp) }\end{array}$ & Jumlah (Rp) \\
\hline 1. & 89.029 & 5.538 & 9,5 & $94.576,5$ \\
2. & 70.325 & 6.689 & 9,5 & $77.023,5$ \\
3. & 79.400 & 11.228 & 9,5 & $90.637,5$ \\
Jumlah & $\mathbf{2 3 8 . 7 5 4}$ & $\mathbf{2 3 . 4 5 5}$ & $\mathbf{2 8 , 5}$ & $\mathbf{2 6 2 . 2 3 7 , 5}$ \\
Rata-rata & $\mathbf{7 9 . 5 8 4}$ & $\mathbf{7 . 8 1 8}$ & $\mathbf{9 , 5}$ & $\mathbf{8 7 . 4 1 2 , 5}$ \\
\hline
\end{tabular}

Tabel 9 menunjukkan bahwa besarnya total biaya tetap yang dikeluarkan oleh tiga orang perajin agroindustri tahu dalam satu kali proses produksi sebesar Rp. 262.237,5 dengan rata-rata $\mathrm{Rp}$ 87.412,5 dari penjumlahan antara biaya Pajak bumi dan bangunan Rp. 238.754 biaya penyusutan alat sebesar Rp. 23.455 dan bunga modal Rp. 9,5. Lebih jelasnya bisa dilihat pada Lampiran 4.
2. Biaya variabel (variabel cost) adalah biaya yang besar kecilnya dipengaruhi oleh besar kecilnya produksi, dan sifatnya habis dalam satu kali proses produksi, yang terdiri dari biaya penyediaan bahan baku (sarana produksi) dan tenaga kerja. Tabel 10 merupakan perincian dari biaya variabel yang dikeluarkan oleh agroindustri tahu.

Tabel 10. Rata-rata Biaya Variabel Pada Usaha Agroindustri Tahu dalam Satu Kali Proses Produksi di Desa Parigi

\begin{tabular}{crrr}
\hline No. Responden & $\begin{array}{r}\text { Sarana Produksi } \\
(\mathbf{R p})\end{array}$ & Tenaga Kerja $(\mathbf{R p})$ & \multicolumn{1}{c}{ Jumlah $(\mathbf{R p})$} \\
\hline 1. & 713.500 & 120.000 & 833.500 \\
2. & 540.000 & 80.000 & 620.000 \\
3. & 826.000 & 112.500 & 938.500 \\
Jumlah & $\mathbf{2 . 0 7 9 . 5 0 0}$ & $\mathbf{3 1 2 . 5 0 0}$ & $\mathbf{2 . 3 9 2 . 0 0 0}$ \\
Rata-rata & $\mathbf{6 9 3 . 1 6 6}$ & $\mathbf{1 0 4 . 1 6 6}$ & $\mathbf{7 9 7 . 3 3 3}$ \\
\hline
\end{tabular}


Tabel 10 menunjukkan bahwa besarnya total biaya variabel yang dikeluarkan oleh tiga orang perajin agroindustri tahu di Desa Parigi dalam satu kali proses produksi adalah Rp. 2.392.000 dengan rata-rata sebesar Rp. 797.333, terdiri dari total biaya sarana produksi Rp. 2.079.500 dengan rata-rata sebesar 693.166 ditambah total biaya tenaga kerja Rp. 312.500 dengan rata-rata sebesar
104.166, untuk lebih jelasnya bisa dilihat pada Lampiran 5.

3. Biaya total merupakan penjumlahan antara biaya tetap total dengan biaya variabel total. Biaya total pada tiga orang perajin agroindustri tahu di Desa Parigi dalam satu kali proses produksi seperti pada tabel berikut.

\section{T abel 11. Rata-rata Biaya Total Pada Usaha Agroindustri Tahu dalam Satu Kali Proses Produksi di Desa Parigi}

\begin{tabular}{crrr}
\hline No. Responden & $\begin{array}{r}\text { Total Biaya Tetap } \\
(\mathbf{R p})\end{array}$ & $\begin{array}{c}\text { Total Biaya } \\
\text { Variabel (Rp) }\end{array}$ & Biaya Total (Rp) \\
\hline 1. & $94.576,5$ & 833.500 & 928.067 \\
2. & $77.023,5$ & 620.000 & 697.014 \\
3. & $90.637,5$ & 938.500 & 1.029 .128 \\
Jumlah & $\mathbf{2 6 2 . 2 3 7 , 5}$ & $\mathbf{2 . 3 9 2 . 0 0 0}$ & $\mathbf{2 . 6 5 4 . 2 0 9}$ \\
Rata-rata & $\mathbf{8 7 . 4 1 2 , 5}$ & $\mathbf{7 9 7 . 3 3 3}$ & $\mathbf{8 8 4 . 7 3 6}$ \\
\hline
\end{tabular}

Tabel 11 menunjukkan bahwa biaya total yang dikeluarkan pada tiga orang perajin agroindustri tahu di Desa Parigi dalam satu kali proses produksi sebesar Rp. 2.653.723,5 dengan rata-rata Rp. 884.574,5 dari hasil penjumlahan ratarata biaya tetap Rp. 87.241 dan rata-rata biaya variabel Rp. 797.333.

\begin{abstract}
Analisis Penerimaan Agroindustri Tahu
Untuk memperoleh penerimaan pada seorang perajin agroindustri tahu di Desa parigi ini dihitung dengan cara mengalikan hasil produksi tahu dalam satu kali proses produksi dengan harga jual saat penelitian. Tabel berikut merupakan rincian dari Penerimaan hasil agroindustri tahu di Desa Parigi untuk satu kali proses produksi.
\end{abstract}


Tabel 12. Rata-rata Penerimaan Usaha Agroindustri Tahu dalam Satu Kali Proses Produksi di Desa Parigi

\begin{tabular}{crcr}
\hline No. Responden & Produk (buah) & $\begin{array}{c}\text { Harga Produk } \\
(\text { Rp/buah })\end{array}$ & Penerimaan (Rp) \\
\hline 1. & 4.984 & 300 & 1.495 .200 \\
2. & 3.600 & 300 & 1.080 .000 \\
3. & 5.555 & 300 & 1.665 .000 \\
Jumlah & $\mathbf{1 4 . 1 3 4}$ & & $\mathbf{4 . 2 4 0 . 2 0 0}$ \\
Rata-rata & $\mathbf{4 . 7 1 1 , 3 3}$ & $\mathbf{3 0 0}$ & $\mathbf{1 . 4 1 3 . 4 0 0}$ \\
\hline
\end{tabular}

Tabel 12, menunjukkan bahwa total penerimaan pada tiga orang perajin agroindustri tahu di Desa Parigi dalam satu kali proses produksi Rp. 4.240.200 dengan rata-rata 1.413 .400 dari rata-rata total produksi tahu 4.711,33 buah, dikalikan dengan harga produk Rp. 300 per buah. Untuk rinciannya bisa di lihat pada Lampiran 7.

Tabel 13. Rata-rata Pendapatan dari Usaha Agroindustri Tahu dalam Satu Kali Proses Produksi di Desa Parigi

\begin{tabular}{crrr}
\hline No. Responden & $\begin{array}{c}\text { Biaya Total } \\
(\mathbf{R p})\end{array}$ & Penerimaan $(\mathbf{R p})$ & Pendapatan(Rp) \\
\hline 1. & 928.067 & 1.495 .200 & 567.133 \\
2. & 697.014 & 1.080 .000 & 382.986 \\
3. & 1.029 .128 & 1.665 .000 & 635.872 \\
Jumlah & $\mathbf{2 . 6 5 4 . 2 0 9}$ & $\mathbf{4 . 2 4 0 . 2 0 0}$ & $\mathbf{1 . 5 8 5 . 9 9 1}$ \\
Rata-rata & $\mathbf{8 8 4 . 7 3 6}$ & $\mathbf{1 . 4 1 3 . 4 0 0}$ & $\mathbf{5 2 8 . 6 6 3}$ \\
\hline
\end{tabular}

Tabel 13 menunjukkan pendapatan yang diperoleh tiga orang perajin agroindustri tahu di Desa Parigi dalam satu kali proses produksi sebesar Rp. 1.585.991 dengan

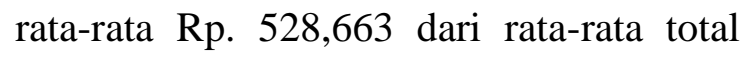
penerimaan Rp. 1.413.400 dikurangi total biaya Rp. 2.654.209 dengan rata-rata Rp. 884.736 rinciannya bisa dilihat pada Lampiran 7.
Analisis Pendapatan Agroindustri Tahu Pendapatan atau keuntungan adalah selisih antara penerimaan dengan total biaya variabel untuk penerimaan pada tiga orang perajin agroindustri tahu di Desa Parigi dapat dilihat pada Tabel berikut. 
Tabel 14. Rata-rata Penerimaan, Biaya dan R/C Pada Usaha Agroindustri Tahu dalam Satu Kali Proses Produksi di Desa Parigi

\begin{tabular}{crrr}
\hline No. Responden & Penerimaan (Rp) & Biaya (Rp) & \multicolumn{1}{c}{ R/C } \\
\hline 1. & 1.495 .200 & 928.067 & 1,61 \\
2. & 1.080 .000 & 697.014 & 1,54 \\
3. & 1.665 .000 & 1.029 .128 & 1,61 \\
Jumlah & $\mathbf{4 . 2 4 0 . 2 0 0}$ & $\mathbf{2 . 6 5 4 . 2 0 9}$ & $\mathbf{4 , 7 6}$ \\
Rata-rata & $\mathbf{1 . 4 1 3 . 4 0 0}$ & $\mathbf{8 8 4 . 7 3 6}$ & $\mathbf{1 , 5 8}$ \\
\hline
\end{tabular}

Berdasarkan hasil penghitungan diketahui bahwa pada tiga orang perajin agroindustri tahu di Desa Parigi dalam satu kali proses produksi memiliki nilai $\mathrm{R} / \mathrm{C}$ rata-rata 1,58. Hal ini menunjukkan bahwa dari setiap satu rupiah biaya yang dikeluarkan, perajin akan memperoleh penerimaan Rp. 1,58 dan pendapatan atau keuntungan Rp. 0,5 rupiah, sehingga dapat dikatakan bahwa usaha agroindustri tahu menguntungkan dan layak untuk diteruskan.

\section{KESIMPULAN DAN SARAN}

\section{Kesimpulan}

1. Besarnya rata-rata biaya yang dikeluarkan (biaya tetap dan biaya variabel) dari agroindustri tahu dalam satu kali proses produksi di Desa Parigi Kecamatan Parigi Kabupaten Pangandaran adalah sebesar Rp 884.736,-

2. Hasil rata-rata Produksi tahu dalam satu kali proses produksi di Desa Parigi Kecamatan Parigi
Kabupaten Pangandaran dari tiga perajin sebanyak 4.711,33 buah dengan harga pada saat penelitian sebesar Rp 300 per buah Maka rata-rata penerimaan sebesar $\mathrm{Rp}$. 1.413.400,-

3. Rata-rata Pendapatan yang diperoleh dari agroindustri tahu dalam satu kali proses produksi dari tiga perajin di Desa Parigi Kecamatan Parigi Kabupaten Pangandaran adalah sebesar $\mathrm{Rp}$ $528,663,-$

4. Rata-rata R/C yang diperoleh dari agroindustri tahu dalam satu kali proses produksi dari tiga perajin di Desa Parigi Kecamatan Parigi Kabupaten Pangandaran adalah 1,58, sehingga dapat dikatakan bahwa usaha agroindustri tahu menguntungkan dan layak untuk diteruskan karena nilai $\mathrm{R} / \mathrm{C}$ nya lebih dari 1. 


\section{Saran}

Berdasarkan hasil pembahasan dan kesimpulan, maka disarankan:

1. Perajin untuk mempertahankan usahanya, karena usaha tahu layak untuk dilaksanakan, bahkan perlu ditingkatkan lagi agar mendapatkan keuntungan yang lebih besar.

2. Perajin untuk meningkatkan manajemennya khususnya dalam masalah keuangan, agar usaha yang dikelola dapat terkontrol posisi keuangannya.

3. Lebih meningkatkan kerjasama dengan penyedia bahan baku.

\section{DAFTAR PUSTAKA}

Adisarwanto, T. 2008. Kedelai. Penebar Swadaya. Jakarta.

Daniel, M. 2002. Metode Penelitian Sosial Ekonomi. Bumi Aksara. Jakarta.

Soekartawi. 2002. Ilmu Usahatani. UI Press. Jakarta.

Sudaryanto dan Syafa'at, 2002. Kebijaksanaan dalam Pengembangan Agribisnis, Salemba Empat. Jakarta.

Sugiyono. 2007. Metode Penelitian Kuantitatif Kualitatif dan $R \& D$. Alfabeta. Bandung.

Suratiyah, 2006. Ilmu Usahatani. Penebar Swadaya. Jakarta.

Hartono. 2007. Geografi 2 Jelajah Bumi dan Alam Semesta. CV Citra Praya. Jakarta. 